\title{
Medullary Thyroid Carcinoma: Why Is Specialization Mandatory?
}

\author{
Theresia Weber \\ Department of Endocrine Surgery, Katholisches Klinikum, Mainz, Germany
}

\section{Keywords}

Medullary thyroid carcinoma - Calcitonin .

Thyroidectomy · Lymph node metastases · Endocrine surgery

\section{Summary}

Medullary thyroid carcinoma (MTC) represents a distinct form of thyroid cancer with a potentially aggressive behavior, early lymph node metastases, and sporadic as well as hereditary forms. Only surgery with total thyroidectomy and lymph node dissection is able to achieve biochemical cure. Due to the uncommon nature of MTC, a specialization in endocrine surgery for diagnosis as well as therapy of MTC seem to be mandatory for a successful treatment. Knowledge of genotype-phenotype correlations for hereditary forms or routine calcitonin screening for sporadic forms is important to analyze preoperative findings and plan surgical procedures. Postoperative follow-up depends on biochemical cure or monitoring for patients with elevated calcitonin levels.

(C) 2018 S. Karger GmbH, Freiburg

\section{Introduction}

According to the data of the Robert Koch Institute, which is responsible for German cancer statistics, the estimated incidence of thyroid cancer is 6,700 cases/year in 2018. The incidence of medullary thyroid carcinoma (MTC) in Germany can only be related to other European countries such as Denmark with 0.2 cases per 100,000 inhabitants per year [1]. In the USA, medullary thyroid carcinoma accounts approximately for $1-2 \%$ of thyroid cancers [2].

Data from this manuscript have in part been presented at the symposium 'Frontiers in Surgical Evolution' on September 21, 2018 in honor of Prof. Dr. Ernst Klar, Rostock, Germany.
In 1959, Hazard et al. [3] histologically described MTC for the first time. Williams [4] discovered in 1966 that MTC derived from the parafollicular C cells, and only 2 years later, Tashjian and Melvin [5] showed that these cells produce calcitonin. During the next decades, many physicians and endocrine surgeons observed an increasing number of familial forms of MTC, but it took quite a long time until molecular techniques were able to identify mutations of the RET proto-oncogene responsible for hereditary MTC. In 1993 [6, 7], germline mutations of the RET proto-oncogene, located on chromosome 10q11.2, were found to be responsible for the hereditary forms of MTC (FMTC) and multiple endocrine neoplasia (MEN2A and MEN2B) syndromes. These findings enabled not only a completely new insight in the pathogenesis of MTC but the results of molecular genetics also justified to perform prophylactic thyroidectomies in patients at risk for MEN2A [8]. In 2015, the revised American Thyroid Association (ATA) guidelines for the management of medullary thyroid carcinoma described the most common 17 mutations of the RET proto-oncogene and their risk for developing MTC as well as pheochromocytoma and hyperparathyroidism [2].

\section{Diagnosis and Surgical Therapy of Medullary Thyroid Carcinoma}

While the rate of surgery performed for hereditary MTC was as high as $66 \%$ during the 1990 s [9], it has now been decreasing constantly to about $20 \%$ during the last years (table 1 ). Today, physicians see mainly sporadic forms of MTC, with tumors often presenting as quite unremarkable thyroid nodules in ultrasound. A multicenter analysis of the results of 641 MTC lesions which underwent fine needle aspiration cytology showed relatively heterogeneous results ranging from 12.5 to $88.2 \%$ [10].

Moley and colleagues found out that more than $70-75 \%$ of the patients presenting with palpable MTC have lymph node involvement and that $10 \%$ already have distant metastases [11, 12]. Therefore, surgical procedures for MTC do not only require a meticulous

\section{KARGER}

() 2018 S. Karger GmbH, Freiburg

Fax +497614520714 
Table 1. Time trends of sporadic and hereditary medullary thyroid carcinoma (MTC) between 1994-2000 and 2009-2018

\begin{tabular}{lll}
\hline & $1994-2000$ & $03 / 2009-09 / 2018$ \\
\hline Patients, n & 36 & 27 \\
Sporadic/hereditary MTC, \% & $44 / 66$ & 92 / 8 \\
Preoperative calcitonin levels, pg/ml & $44-22,280$ & $15-16,000$ \\
T categories: pT1 / pT2 / pT3/ pT4, \% & $17 / 72 / 0 / 11$ & $56 / 26 / 11 / 7$ \\
Lymph node metastases, \% & 75 & 37 \\
Biochemical cure, \% & 44 & 72 \\
5-year survival rate, \% & 96 & 96 \\
Recurrence-free survival, \% & 71 & 82 \\
\hline
\end{tabular}

technique for total thyroidectomy but also a routine or systematic lymph node dissection of the central and lateral cervical compartment of the neck to provide the goal of biochemical cure (= postoperative normalization of calcitonin) $[9,13,14]$.

In the majority of studies, prognosis of MTC is related to the patient's age at diagnosis, male gender, extrathyroidal invasion, lymph node metastases, and distant metastases, mostly detected in the lung, the liver, and the bones. Currently, biochemical cure rates of $62-76 \%$ are reported in experienced centers [15-17].

\section{Why Is Specialization Mandatory?}

With an increasing number of sporadic MTC appearing often as inconspicuous thyroid nodules, preoperative calcitonin screening provides an important tool to discriminate between benign and malignant findings. During the last years, biochemical cure rates of patients with sporadic MTC improved constantly in the era of calcitonin screening [17]. Therefore, the German Association of Endocrine Surgeons recommends routine calcitonin screening before every thyroid operation to exclude or detect MTC $[18,19]$. The interpretation of calcitonin levels, however, can be challenging because of a variety of falsely high levels caused by medication such as proton pump inhibitors or lithium, alcohol abuse, renal insufficiency, or children under 3 years of age. To assess possible problems of the interpretation of calcitonin testing, a differentiated knowledge of these side effects and the various calcitonin assays seems mandatory. In female patients with calcitonin levels $\geq 35 \mathrm{pg}$ / $\mathrm{ml}$ and male patients with calcitonin levels $\geq 46 \mathrm{pg} / \mathrm{ml}$, the risk for MTC is considered to be markedly elevated [20]. Other studies defined $60-65 \mathrm{pg} / \mathrm{ml}$ as cut-off values of calcitonin to detect MTC [21, 22]. Earlier detection of MTC leads to better biochemical cure rates, as shown by Machens and Dralle in 2015 [17].

If calcitonin is elevated in two different blood samples obtained at different visits, further diagnostic should be performed with laboratory tests for catecholamines and adrenal ultrasound or computed tomography (CT) scan to exclude pheochromocytoma to prevent hypertensive crisis during thyroidectomy. A family history should be obtained. Patients with sporadic MTC should be offered a genetic counseling and DNA analysis for RET germline muta- tions. Patients with MEN2B syndrome often have a typical phenotype which can only be noticed by an experienced physician and should be tested for the RET codon M918T mutation.

Operative procedures for MTC require a specialization in endocrine surgery to enforce an oncologic approach for this potentially aggressive cancer in order to achieve the best biochemical cure rates for the patients. In addition, special training is necessary to preserve intraoperatively important structures such as the recurrent laryngeal nerves, the vagal nerves, the spinal accessory nerve, the brachial and cervical plexus, as well as the thoracic duct or the parathyroid glands. Continuous intraoperative nerve monitoring seems to better preserve the recurrent laryngeal nerves, especially from traction to the nerve. The goal of MTC surgery is to be as aggressive as necessary but to preserve all of the important structures and the patient's quality of life.

Total thyroidectomy and compartment-oriented central and ipsilateral lateral lymph node dissection are the recommended procedures for patients with calcitonin levels $>20 \mathrm{pg} / \mathrm{ml}$ and $<200 \mathrm{pg} /$ $\mathrm{ml}$. If calcitonin levels are $\geq 200 \mathrm{pg} / \mathrm{ml}$, the contralateral lateral compartment should be dissected too. Compartment-oriented neck dissection does not only enable better biochemical cure rates but also prevents local recurrence in the neck.

If MTC is diagnosed incidentally by histopathological examination, the results of completion thyroidectomy and lymph node dissection are less favorable than for primary surgery $[9,17]$.

Postoperative biochemical chemical cure rates do not only depend on calcitonin levels or the experience of the surgeon. They are also influenced by important other aspects of MTC such as a more aggressive clinical course due to a somatic RET codon M918T mutation in sporadic MTC [23] or the histopathologic finding of desmoplasia in the tumor tissue, which seems to be the most reliable indicator of metastatic potential of MTC [24]. Both examinations require highly specialized pathologists to describe these conditions.

According to the ATA management guidelines for MTC [2], serum levels of calcitonin and carcinoembryonic antigen (CEA) should be measured 3 months postoperatively, and if undetectable or within the normal range, these should be measured every 6 months for 1 year, and then yearly thereafter. In patients with detectable serum levels of calcitonin and CEA, a follow-up should be provided at least every 6 months. Barbet et al. [25] described the prognostic impact of calcitonin doubling times for follow-up in MTC. If calcitonin doubling times were less than 6 months, 5-year survival rates were $25 \%$ compared to $92 \%$ in those with calcitonin doubling times between 6 and 24 months.

In case of postoperatively elevated calcitonin levels, detection of persistent or recurrent MTC should start with ultrasound, followed by neck and chest CT, contrast-enhanced magnetic resonance imaging of the liver and F-Dopa-PET(positron emission tomography)/CT [26], which seems to have a higher sensitivity compared with FDG(fluorodeoxyglucose)-PET/CT [27]. PET/CT imaging is not only expensive but it should also be analyzed only by experienced nuclear medicine physicians with knowledge of the patient's calcitonin levels.
Weber 
Patients with persistent or recurrent MTC localized to the neck can be subjected to repeated neck surgery [2]. A meta-analysis of 984 patients with reoperations for MTC found an overall calcitonin normalization in $16.2 \%$ [28]. Stratified by operative procedure, selective lymph node removal led to biochemical cure rates of $10.5 \%$ compared to $18.6 \%$ after compartment-oriented lymph node dissection.

For patients with non-resectable distant metastases and progressive disease, tyrosine kinase inhibitors should be considered as systemic therapy, being provided by specialized endocrinologists or oncologists.

MTC is a rare tumor which differs from other forms of thyroid carcinoma due to its potentially aggressive growth, early lymph node metastases, and sporadic as well as hereditary forms. Since surgery is the best therapy, a special training in endocrine surgery is strongly recommended to achieve biochemical cure in these patients.
To educate and train future leaders in endocrine surgery, clinical fellowship programs including clinical workups, operative treatment, and postoperative care are communicated by the American Association of Endocrine Surgeons (AAES). In Europe, fellowship programs are currently being offered by hospitals in Sweden and the UK. A European Board of Surgery Qualification (EBSQ) in endocrine surgery can be obtained by passing an oral examination. Since 2003, 142 candidates have successfully passed the EBSQ exam in endocrine or neck endocrine surgery, 27 of them coming from Germany. In Germany, there are no specialized training programs for endocrine surgeons until now, and the number of positions as chiefs in endocrine surgery, in specialized hospitals, or in an academic setting is low.

\section{Disclosure Statement}

There is no conflict of interest to declare.

\section{References}

1 Mathiesen JS, Kroustrup JP, Vestergaard P, et al: Incidence and prevalence of sporadic and hereditary MTC in Denmark 1960-2014: a nationwide study. Endocr Connect 2018;7:829-839.

2 Wells SA Jr, Asa SL, Dralle H, et al: Revised American Thyroid Association guidelines for the management of medullary thyroid carcinoma. Thyroid 2015;25:567610 .

3 Hazard JB, Hawk WA, Crile G Jr: Medullary (solid) carcinoma of the thyroid; a clinicopathologic entity. J Clin Endocrinol Metab 1959;19:152-161.

$\checkmark 4$ Williams ED: Histogenesis of medullary carcinoma of the thyroid. J Clin Pathol 1966;19:114-118.

5 Tashiian AH Jr, Melvin EW: Medullary carcinoma of the thyroid gland. Studies of thyrocalcitonin in plasma and tumor extracts. N Engl J Med 1968;279:279-283.

6 Donis-Keller H, Dou S, Chi D, et al: Mutations in the RET proto-oncogene are associated with MEN $2 \mathrm{~A}$ and FMTC. Hum Mol Genet 1993;2:851-856.

7 Mulligan LM, Kwok JB, Healey CS, et al: Germ-line mutations of the RET proto-oncogene in multiple endocrine neoplasia type 2A. Nature 1993;363:458-460.

${ }_{8}$ Wells SA Jr, Chi DD, Toshima K, et al: Predictive DNA testing and prophylactic thyroidectomy in patients at risk for multiple endocrine neoplasia type $2 \mathrm{~A}$. Ann Surg 1994;220:237-250

${ }_{9}$ Weber T, Schilling T, Frank-Raue K, Colombo-Benkmann M, Hinz U, Ziegler R, Klar E: Impact of modified radical neck dissection on biochemical cure in medullary thyroid carcinomas. Surgery 2001;130: 1044-1049.

10 Trimboli P, Treglia G, Guidobaldi L, et al: Detection rate of FNA cytology in medullary thyroid carcinoma: a meta-analysis. Clin Endocrinol 2015;82:280-285.

11 Moley JF, DeBenedetti MK: Patterns of nodal metastases in palpable medullary thyroid carcinoma: recommendations for extent of node dissection. Ann Surg 1999;229:880-887.
2 Moley JF: Medullary thyroid carcinoma: management of lymph node metastases. J Natl Compr Canc Netw 2010;8:549-556.

13 Tisell LE, Hansson G, Jansson S, Salander H: Reoperation in the treatment of asymptomatic metastasizing medullary thyroid carcinoma. Surgery 1986;99:60-66.

14 Dralle H, Damm I, Scheumann GF, et al: Compartment-oriented microdissection of regional lymph nodes in medullary thyroid carcinoma. Surg Today 1994;24:112-121.

15 Ito Y, Miyauchi A, Kihara M, Higashiiyama T, Fukushima M, Miya A: Static prognostic factors and appropriate surgical designs for patients with medullary thyroid carcinoma: the second report from a single-institution study in Japan. World J Surg 2018;DOI: 10.1007/s00268-018-4738-z.

16 Jung KY, Kim SM, Yoo WS, Kim BW, Lee YS, Kim KW: Postoperative biochemical remission of serum calcitonin is the best predictive factor for recurrencefree survival of medullary thyroid cancer: a large-scale retrospective analysis over 30 years. Clin Endocrinol 2016;84:587-597.

17 Machens A, Dralle H: Surgical cure rates of sporadic medullary thyroid cancer in the era of calcitonin screening. Eur J Endocrinol 2016;175:291-228.

18 Dralle H, Musholt TJ, Schabram J, et al: German Association of Endocrine Surgeons practice guideline for the surgical management of malignant thyroid tumors. Langenbecks Arch Surg 2013;398:347-375.

19 Musholt TJ, Bockisch A, Clerici T, Dotzenrath C, Dralle H, Goretzki PE: Update of the S2k guidelines: surgical treatment of benign thyroid diseases. Chirurg 2018;89:699-709.

20 Allelein S, Ehlers M, Morneau C, et al: Measurement of basal serum calcitonin for the diagnosis of medullary thyroid cancer. Horm Metab Res 2018;50:23-28.
21 Chambon G, Alovisetti C, Idoux-Louche C, et al: The use of preoperative routine measurement of basal serum thyrocalcitonin in candidates for thyroidectomy due to nodular thyroid disorders: results from 2733 consecutive patients. J Clin Endocrinol Metab 2011;96: 75-81.

22 Kwon H, Kim WG, Choi YM, et al: A cut-off value of basal serum calcitonin for detecting macroscopic medullary thyroid carcinoma. Clin Endocrinol 2015;82: 598-603.

23 Schilling T, Bürck J, Sinn H-P, et al: Prognostic value of codon 918 (ATG $\rightarrow$ ACG) RET proto-oncogene mutations in sporadic medullary thyroid carcinoma. Int J Cancer 2001;95:62-66.

24 Koperek O, Scheuba C, Cherenko M, et al: Desmoplasia in medullary thyroid carcinoma: a reliable indicator of metastatic potential. Histopathology 2008;52:623630.

25 Barbet J, Campion L, Kraeber-Bodéré F, Chatal JF; GTE Study Group: Prognostic impact of serum calcitonin and carcinoembryonic antigen doubling-times in patients with medullary thyroid carcinoma. J Clin Endocrinol Metab 2005;90:6077-6084.

26 Luster M, Karges W, Zeich K, et al: Clinical value of 18-fluorine-fluorodihydroxyphenylalanine positron emission tomography/computed tomography in the follow-up of medullary thyroid carcinoma. Thyroid 2010;20:527-533.

27 Romero-Lluch AR, Cuenca-Cuenca JI, GuerreroVázquez R, et al: Diagnostic utility of PET/CT with 18F-Dopa and 18F-FDG in persistent or recurrent medullary thyroid carcinoma: the importance of calcitonin and carcinoembryonic antigen cutoff. Eur J Nucl Med Mol Imaging 2017;44:2004-2013.

28 Rowland KJ, Jin LX, Moley JF: Biochemical cure after reoperations for medullary thyroid carcinoma: a metaanalysis. Ann Surg Oncol 2015;22:96-102. 